\title{
EDUCAR PARA O PATRIMÔNIO CULTURAL: VALORIZAÇÃO E APROPRIAÇÃO DO CENTRO HISTÓRICO NATALENSE
}

Andréa Virgínia Freire Costa ${ }^{1}$

Patrícia Daliany do Amaral ${ }^{2}$

\section{RESUMO}

Esse artigo apresenta a experiência da realização do Projeto de Extensão Educando para o Patrimônio Cultural (2012/13), focando sua relevância, nos impactos educacionais e sociais e na contribuição para a formação dos discentes participantes. O projeto teve como objetivo realizar uma ação de educação patrimonial no centro histórico de Natal/RN com os moradores da cidade, tendo como atividades principais a capacitação de alunos do IFRN-Campus Natal Cidade Alta, a realização de oficinas de educação patrimonial e visitas ao centro histórico, tendo como embasamento teórico os princípios da educação patrimonial e comunicação interpretativa. Acredita-se que foram gerados resultados positivos na sociedade, com a formação de agentes multiplicadores sobre a importância da preservação do patrimônio cultural, a divulgação e valorização do centro histórico natalense e o desenvolvimento dos sentimentos de apropriação, afetividade e pertencimento, além de promover novos desdobramentos.

Palavras-chave: centro histórico, preservação, formação.

\section{INTRODUÇÃO}

Em 2010, deu-se o tombamento do centro histórico de Natal (composto por parte dos bairros da Cidade Alta e da Ribeira) pelo Instituto do Patrimônio Histórico e Artístico Nacional (IPHAN). Contudo, percebe-se que ainda assim ele é pouco conhecido e apropriado pela sua população. Esse distanciamento dos habitantes da cidade em relação ao seu centro histórico já foi apontado em outros estudos (VELOSO, 2010) e corroborado com o desenvolvimento das atividades acadêmicas no Campus Natal - Cidade Alta do IFRN ${ }^{3}$, quando se percebeu o desconhecimento dos alunos e da comunidade sobre o bairro e seu entorno.

Frente a esse quadro vêm sendo propostas, desde 2009, diversas ações de extensão buscando discutir o valor cultural desse conjunto tombado, bem como suas possibilidades enquanto atividade de lazer para os natalenses e de visitação para os turistas. Em 2012 foi desenvolvido o projeto de pesquisa Estudando o centro histórico de

1 Professora do Campus Cidade Alta, graduada em Direito e Arquitetura e Mestre em Desenvolvimento Urbano.

2 Professora do Campus Cidade Alta, Turismóloga e Mestre em Geografia.

30 citado Campus foi instalado em 2009, no centro histórico da cidade do Natal/RN, em um prédio centenário, tombado pela Fundação José Augusto/SECULT-RN. 
Natal/RN e suas possibilidades para o turismo ${ }^{4}$. Nesse mesmo ano, visando trabalhar de forma mais efetiva com a educação patrimonial, foi executado o projeto de extensão Educando para o patrimônio cultural, em parceria com o IPHAN/ RN. A primeira edição aconteceu de março/2012 a fevereiro/2013, seguida por uma segunda edição no período de junho/2013 a fevereiro/2014. O objetivo era promover uma ação de educação patrimonial que possibilitasse aos moradores da cidade do Natal conhecer seu centro histórico e se apropriarem dele, reforçando sua identidade e contribuindo para sua preservação.

Para alcançar esse fim, o projeto articulou ensino, pesquisa e extensão, por meio de duas atividades principais: a capacitação de alunos do IFRN Campus Natal - Cidade Alta, por meio do Curso de Formação de Tutores em Educação Patrimonial e a realização de oficinas de educação patrimonial e visitas no centro histórico, com participação livre dos interessados, formando grupos heterogêneos com estudantes, donas de casa, profissionais da área do turismo e do setor cultural, dentre outros.

$\mathrm{Na}$ ação efetivada, entende-se educação patrimonial como uma ferramenta essencial no processo de preservação e valorização do patrimônio cultural, indo além da sua divulgação. Compreende-se a necessidade de atuar com vistas à criação de relações de afetividade por parte da comunidade, trabalhando sentimentos relacionados à diversidade cultural, identidade e pertencimento, assim como uma construção coletiva do conhecimento (FLORÊNCIO, 2012). Para isso, utilizou-se como referencial metodológico do curso proposto a comunicação interpretativa, acreditando que para a verdadeira construção de conhecimentos, é necessário mais do que simplesmente comunicar as informações, devendose estabelecer significados e inter-relações (COSTA, 2009). O objetivo maior é proporcionar experiências positivas, despertando o entusiasmo nas pessoas e fazendo com que elas se envolvam com o objeto trabalhado.

\section{VALORIZAÇÃO E APROPRIAÇÃO DO CENTRO HISTÓRICO DE NATAL}

Como já dito, o Projeto de Extensão Educando para o Patrimônio Cultural foi realizado em duas edições. Ambas foram divididas em três módulos, sendo a primeira versão (2012/13) com carga horária de 80h/a, e a segunda (2013/14) com 160h/a.
Na primeira edição, o Módulo 1 foi composto por aulas que abordavam temas relativos à cultura e ao patrimônio cultural; turismo cultural e comunicação interpretativa. Além desses assuntos, também foi feita pesquisa sobre os locais a serem visitados, elaboração coletiva do roteiro, orientação para elaboração do speech $^{5}$ e aulas de campo conduzidas pelos alunos no centro histórico de Natal. O segundo módulo tinha como objetivo melhorar o desempenho dos alunos na condução dos grupos. Assim, houve primeiramente uma avaliação aprofundada das atividades realizadas no primeiro módulo, com feedback individual e coletivo para os alunos sobre sua atuação, incluindo um momento de autoavaliação. Em seguida, buscou-se aprofundar alguns assuntos trabalhados no Módulo 1, como patrimônio cultural e história da cidade do Natal (com enfoque na Ribeira). Por fim, diversas aulas práticas foram realizadas, com inserção de atividades planejadas pelos alunos. O terceiro e último módulo foi eminentemente prático, com a realização de seis visitas ao centro histórico de Natal, abertas ao público em geral. Cada tutor era responsável pela apresentação de alguns locais visitados e de conduzir os visitantes entre os espaços selecionados no roteiro.

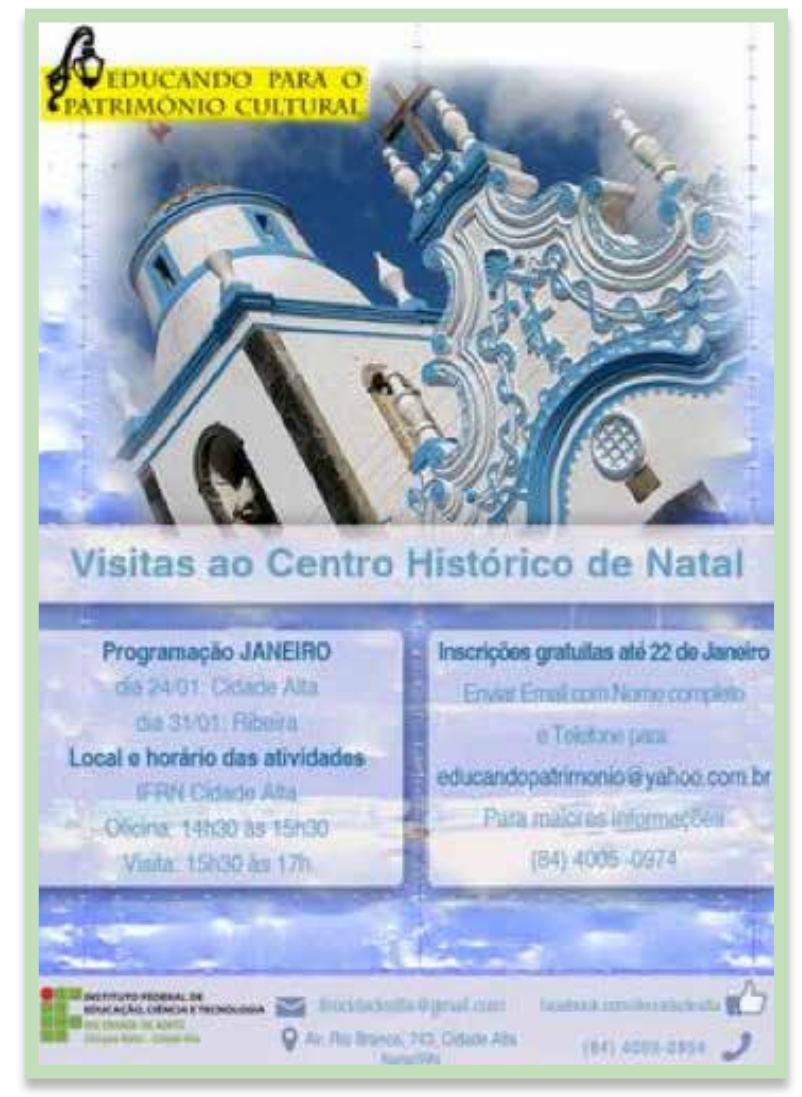

4 AMARAL, Patrícia. D. A. do; GOMES, Fábio H.; NASCIMENTO, Isabella L., 2012.

50 speech é a fala daquele que está conduzindo o grupo, composta pelos cumprimentos aos participantes, as informações a serem passadas sobre o objeto visitado, bem como recomendações relativas à visita. 


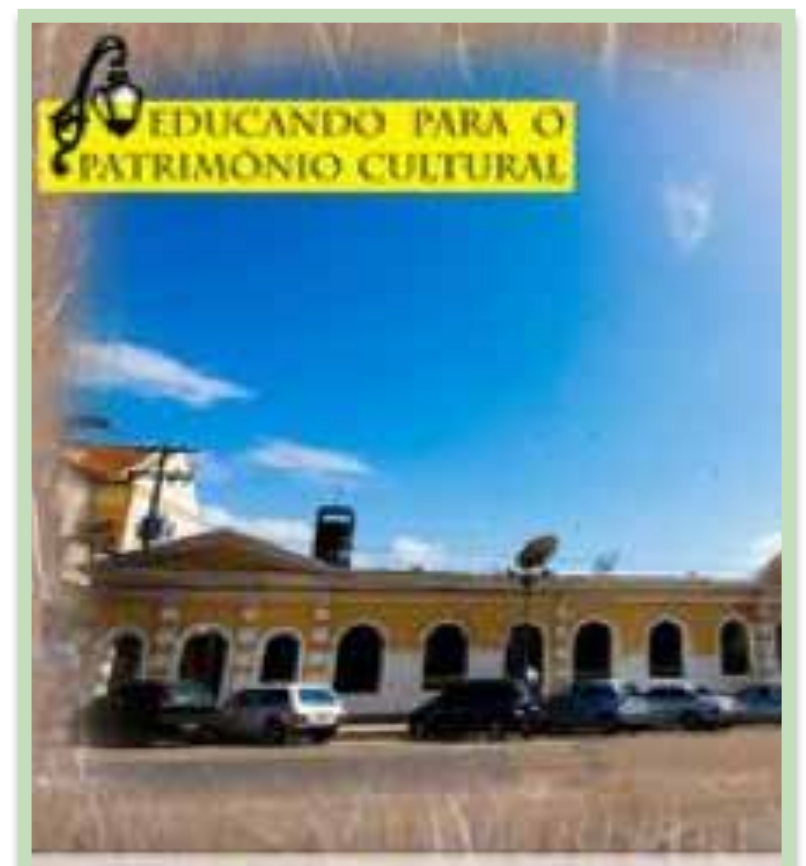

\section{Visitas ao Centro Histć}

Programaço FEVEREIRO

Figura 1: Cartazes de divulgação das atividades práticas do projeto

$\mathrm{Na}$ segunda edição, aumentou-se a carga horária para $160 \mathrm{~h} / \mathrm{a}$ e se modificou o conteúdo dos módulos. Sendo assim, no primeiro módulo, além das aulas teóricas sobre cultura, patrimônio, turismo cultural e comunicação interpretativa foram acrescidas aulas de campo a espaços culturais da cidade, como o Museu de Arte Sacra, o Memorial Câmara Cascudo e o Museu de Cultura Popular. No Módulo 2, focou-se nas técnicas de guiamento e na elaboração do speech, com a realização de aulas práticas a fim de trabalhar o conteúdo discutido em sala de aula. No último módulo o foco foi o desempenho dos alunos na condução do grupo. Para isso, a avaliação feita pelo grupo (alunos e professoras) contribuiu para a realização de ajustes no speech e melhoras no desempenho dos alunos na condução dos grupos, que foram sendo aprimorados com as diversas visitas realizadas. Foi solicitado aos alunos ainda um relatório final sobre sua participação no projeto.

A experiência vivenciada durante a realização do projeto Educando para o patrimônio cultural trouxe uma série impactos, internos e externos ao IFRN. Sobre a contribuição para a formação dos estudantes, cabe destacar que com a finalização da primeira edição, foi solicitado aos alunos que avaliassem o curso e a contribuição para sua formação profissional. Foram apontados pelos tutores os seguintes pontos positivos: bom desempenho dos tutores no desenvolvimento das atividades; empenho, entusiasmo e esforço dos tutores no decorrer do projeto; busca de informações que não são de conhecimento comum. Os alunos apontaram ainda que, mesmo reconhecendo a importância dos conteúdos teóricos trabalhados, entendiam como extremamente relevantes as atividades práticas de guiamento para seu melhor desempenho enquanto tutores. Vários deles relataram espontaneamente que a participação no projeto havia contribuído para sua formação enquanto guias de turismo.

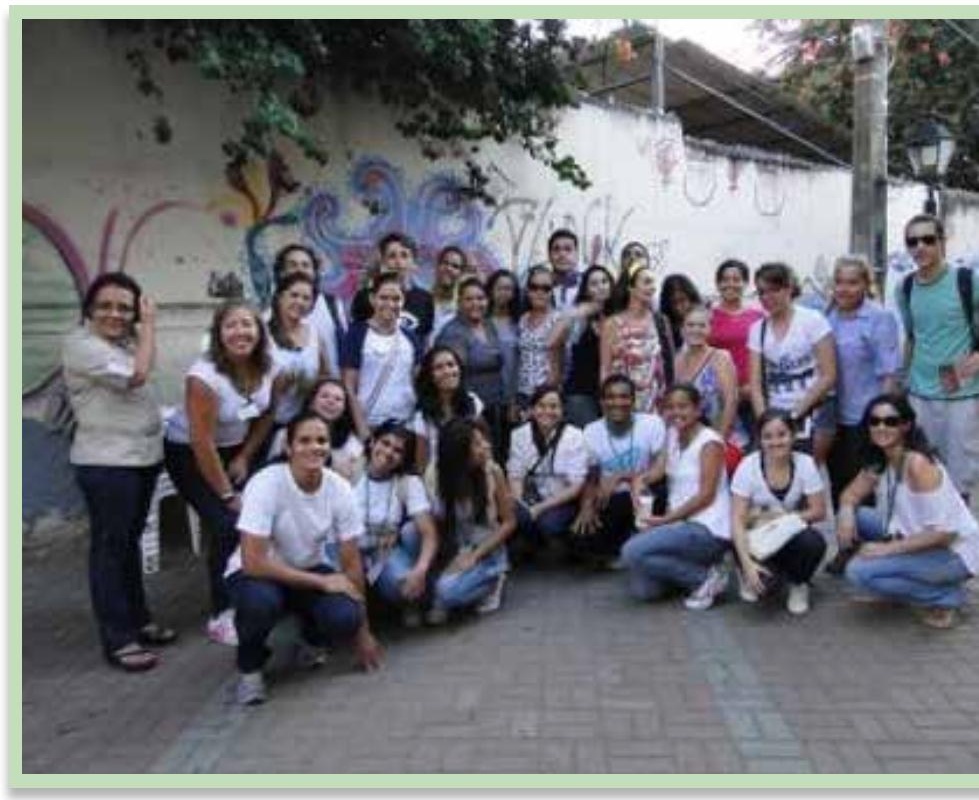

Figura 2: Grupo de alunos que participou das atividades

No que tange aos impactos sociais do projeto, cabe destacar a boa repercussão na mídia, tendo sido realizadas entrevistas em emissoras de TV e rádios locais, publicação em jornal e em blogs, fato que ocasionou uma maior busca pelas atividades ofertadas, demonstrando a vontade da comunidade em participar do projeto. Assim, em função da demanda, resolveu-se inscrever quarenta participantes para cada dia de atividade. Contudo, por se tratar de uma programação gratuita, alguns inscritos não compareceram nas datas previstas, fazendo com que as oficinas e visitas tivessem de 20 a 25 participantes, totalizando uma média de 100 participantes por edição do projeto.

Ao final da primeira edição do projeto, foi aplicado um questionário de avaliação da atividade realizada junto aos participantes da oficina e da visita. Observou-se que a atividade foi bem avaliada pelos participantes, com mais de 
$80 \%$ (91 pessoas) respondendo que a oficina e a visita foram ótimas. Cabe ressaltar que nenhum respondente classificou nenhuma das ações como ruim ou péssima. Quanto ao desempenho dos tutores, verificou-se que houve uma avaliação positiva pelos participantes do projeto, com cerca de 55\% considerando-o ótimo (61 respondentes).

A última pergunta do questionário ( $A$ atividade ajudou a perceber a importância do nosso centro histórico? Por quê?) tinha como opções de resposta apenas sim e não. Todos os participantes responderam que sim, complementando suas respostas com a justificativa. Cabe destacar algumas delas: "[...] o contato ajuda muito na criação de laços com o lugar e descoberta do papel histórico"; "A oficina e a visita nos ajuda a andar pela Ribeira com outros olhares"; "Pude avaliar melhor o valor histórico do bairro da Ribeira, por meio das curiosidades dos prédios e ruas".

Na segunda edição, não foram aplicados questionários, mas feitas avaliações periódicas após o final de cada módulo com os participantes do projeto. Estes mencionaram, o prazer de ter participado e ressaltaram sua importância para a sua formação e apropriação daqueles espaços percorridos. Foi destacado como um ponto bastante positivo nessa segunda edição do projeto a visita aos espaços culturais da cidade, tanto por possibilitar o conhecimento das condições dos locais, apreciação do seu acervo e avaliação do desempenho dos condutores de grupo dos espaços.

\section{CONCLUSÃO}

Como resultados derivados desse projeto, cabe destacar a pesquisa sobre os espaços inseridos no roteiro, que culminou com a elaboração do guia de visitação do centro histórico de Natal, publicado pela Editora do IFRN em 2014, em versão digital; a publicação de artigos tendo esse projeto como objeto de pesquisa ${ }^{6}$ e o desenvolvimento de projeto na Incubadora Cultural do IFRN por ex-alunos participantes do projeto, tendo a visitação ao centro histórico natalense como produto a ser formatado em negócio.

Com a realização das atividades propostas nesse projeto, acredita-se que foram gerados impactos positivos na sociedade, como o levantamento e divulgação de informações acerca dos locais a serem conhecidos; a formação de agentes multiplicadores sobre a importância da preservação do patrimônio cultural da cidade; e a valorização do centro histórico de Natal e o desenvolvimento dos sentimentos de apropriação, afetividade e pertencimento.

\section{REFERENCIAS}

COSTA, Flávia Roberta. Turismo e patrimônio cultural: interpretação e qualificação. São Paulo: Editora SENAC, 2009.

FLORÊNCIO, Sônia Regina Rampim. Educação Patrimonial: um processo de mediação. In: TOLENTINO, Átila Bezerra (Org.). Educação patrimonial: reflexões e práticas. João Pessoa: Superintendência do Iphan na Paraíba, 2012. p. 22-29.

VELOSO, M. et al. Crônica de uma morte anunciada: Arquitetura moderna em Natal x Copa de 2014. In: Seminário Docomomo Norte Nordeste, 3, 2010. Anais.... João Pessoa: UFPB, 2010. Disponível em: <http://www.docomomonortenordeste.com.br/ artigos/TC_SEC2_7.pdf>. Acesso em: 21 jan. 2012. 